\title{
A genderwise comparison of sleep habits of a sample adult population of Kathmandu
}

Binu Gorkhali

\section{Author(s) info:}

Nepal Institute of Health

Sciences, Jorpati, Gokarneswor-5,

Kathmandu, Nepal

\section{Correspondence:}

\section{Binu Gorkhali}

Email:

binugr32@gmail.com

DOI :

https://doi.org/10.3126/jpsn.v1i2.42276

\begin{abstract}
Introduction: A consolidated sleep of 7-9 hours has recuperative effect and improves cognitive function. Relating to their differences in sociodemograpic roles and physiological responses, men and women have different sleep characteristics. Gender differences in Nepalese population has not been reported. The knowledge could be helpful in addressing their sleep disorders.
\end{abstract}

Materials and methods: Sleep-related information was collected by means of questionnaires from randomly selected adults visiting a blood donation center in Kathmandu.

Results: Complete response was obtained from 442 participants - 317 males and 125 females, with comparable mean age. Most (83.26\%) participants had 7-9 hours of sleep. Women went to bed earlier ( $9.43 \mathrm{pm} \pm 57 \mathrm{~min}$ vs $10.05 \mathrm{pm} \pm 77 \mathrm{~min}$ in men, $\mathrm{p}=0.006$ ) as well as woke up earlier (5.37 am $\pm 48 \mathrm{~min}$ vs $6.04 \mathrm{am} \pm 91 \mathrm{~min}$ in men, $\mathrm{p}<0.001)$. Total duration of sleep was comparable between the groups (nearly 8 hours \pm 1 hour). Age correlated inversely with sleep duration in men $(p=0.003)$ but not in women.

Conclusions: Most participants have adequate sleep duration. Women go to bed earlier and wake up earlier than men, but have about equal duration of sleep.

Keywords: Gender, adults, sleep duration, sleep habit.

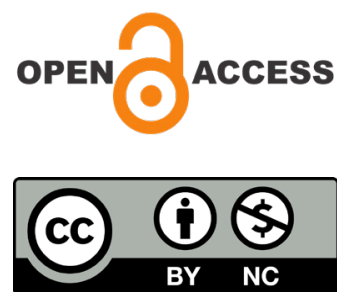

(C) JPSN 


\section{INTRODUCTION}

Sleep is a circadian event recognized as a basic human need and takes up more portion of daily time than most other activities. A consolidated sleep has the effect of restoring health, removing the feeling of fatigue, and improving cognitive ability.[1] As a result, the person feels ready to face the challenges of a new day. Sleep is also helpful in maintaining metabolic-caloric balance, thermoregulation, and immune competence.[2] Different studies have observed a U-shaped association between sleep and mortality. Short as well as long sleep durations are associated with greater mortality risk than intermediate sleep durations.[3-6] Duration of sleep is even related to cognitive function of an individual.[7,8]

There are multiple differences between males and females both in normal physiology and in the pathophysiology of disease, including cardiovascular, musculoskeletal, and immune systems as well as the cellular mechanisms of sex steroid hormone actions on non-reproductive tissues.[9] Gender differences also apply to psychological and mental health as well as sociodemographic factors.[9]

Sleep has physiological, psychological and cognitive associations and different sleep disorders are recognized. Sex difference also probably shapes sleep duration in the general population. Women usually have longer sleep duration than men but also have lower sleep quality, resulting in greater fatigue.[10] Gender comparisons of sleep has not been reported in the Nepalese population.

\section{MATERIALS AND METHODS}

A cross-sectional, descriptive study was undertaken at the premises of the Center for Blood Transfusion Services, Exhibition Road, Kathmandu in the period of August-October, 2014. The place was selected for the convenience of recruiting healthy adults of the general public. Apparently healthy adult males and females who visited the Center were randomly selected and consisted mostly of blood donors or their accompanying friends. Regular use of any medications, occupation requiring shift and night duties, grossly irregular habits of sleep, frequent consumption of alcohol, and other conditions known to interfere with sleep were the exclusion criteria.
Prints of questionnaires about the general and sleep habit information were handed out and collected back after about 10 minutes. The return of the filled up forms by the participant was also regarded as consent to participate in the study. Partially filled forms were not considered for the study. The questionnaires did not reveal identity of the participant. The time of going to bed and time of waking up were to be answered on the basis of the usual times or the average over the past one week of the participant. Infrequent large changes in either time due to different reasons were not to be considered for the sleep habit information. Analyses of the sleep/wake up times and sleep duration times were done in decimal system and the final values were converted to sexagesimal system (hour-minute-seconds system) for convenience in understanding.

According to the duration of night sleep, participants were classified as (a) less than 7 hours sleep, (b) 7-9 hours of sleep and (c) more than 9 hours of sleep.[11] Comparison of average sleep habits of males versus females, age comparison of different sleep categories, and correlation of age with sleep duration in males and females were done with appropriate tests on SPSS 16.0 and taking $\mathrm{p}$ value of 0.05 or less as level of significance.

\section{RESULTS}

Complete response was obtained from 317 males and 125 females (total 442). Their average age was $29.6 \pm 8.6$ years and body mass index (BMI) was $23.88 \pm 5.3 \mathrm{~kg} / \mathrm{m}^{2}$. The two groups had comparable average age and BMI (Table 1).

Regarding sleeping habit, females went to bed significantly earlier as well as woke up significantly earlier in the morning than the males. However, they had almost identical total duration of sleep hours. In both groups, most of the participants had sleep duration of 7 to 9 hours and the distribution of sleep duration was not significantly different (Table 2).

Overall, $83.26 \%$ participants $(\mathrm{n}=368)$ had a sleep duration of 7-9 hours; $9.5 \%(\mathrm{n}=42)$ had less than 7 hours and $7.24 \%(n=32)$ had more than 9 hours of average duration of sleep. There was significant difference in the age of participants in these sleep categories ( $\mathrm{p}$ value $=0.028$, ANOVA). Younger people slept for more hours and older people had less sleep hours (Figure 1). The mean age of 
Table 1: Gender comparison in general characteristics of participants

\begin{tabular}{|l|c|c|c|c|}
\hline \multirow{2}{*}{ Characteristics } & \multicolumn{2}{|c|}{ Gender } & \multicolumn{2}{c|}{ ANOVA } \\
\cline { 2 - 5 } & Male (n=317) & Female $(\mathbf{n}=\mathbf{1 2 5})$ & F value & P value \\
\hline Age, years & $29.5 \pm 7.97$ & $29.81 \pm 10.05$ & 0.118 & 0.732 \\
\hline Height, cms & $165.78 \pm 8.79$ & $156.68 \pm 9.12$ & 83.179 & $<0.001$ \\
\hline Weight, $\mathrm{Kg}$ & $67.83 \pm 10.26$ & $58.42 \pm 10.67$ & 63.814 & $<0.001$ \\
\hline BMI, $\mathrm{Kg} / \mathrm{m}^{2}$ & $24.08 \pm 5.26$ & $23.41 \pm 5.24$ & 1.30 & 0.254 \\
\hline
\end{tabular}

Table 2: Gender-wise comparisons of age and sleep habits of participants

\begin{tabular}{|c|c|c|c|c|}
\hline \multirow{2}{*}{\multicolumn{2}{|c|}{ Characteristics }} & \multicolumn{2}{|c|}{ Gender } & \multirow{3}{*}{$\begin{array}{r}\text { P value } \\
0.006\end{array}$} \\
\hline & & \multirow{2}{*}{$\begin{array}{c}\text { Male }(\mathbf{n}=317) \\
10.05 \mathrm{pm} \pm 77 \mathrm{~min}\end{array}$} & \multirow{2}{*}{$\begin{array}{l}\text { Females }(\mathbf{n}=\mathbf{1 2 5}) \\
9.43 \mathrm{pm} \pm 57 \mathrm{~min}\end{array}$} & \\
\hline \multirow{3}{*}{$\begin{array}{l}\text { Sleep habit } \\
\text { (independent t test) }\end{array}$} & Time to bed ${ }^{* *}$ & & & \\
\hline & Wake up time ${ }^{* * *}$ & $6.04 \mathrm{am} \pm 91 \mathrm{~min}$ & $5.37 \mathrm{am} \pm 48 \mathrm{~min}$ & $<0.001$ \\
\hline & Duration of sleep & $7 \mathrm{hr} 50 \mathrm{~min} \pm 65 \mathrm{~min}$ & $7 \mathrm{hr} 54 \mathrm{~min} \pm 64 \mathrm{~min}$ & 0.602 \\
\hline \multirow{3}{*}{$\begin{array}{l}\text { Category by sleep } \\
\text { duration (Chi square } \\
\text { test) }\end{array}$} & Less than 7 hours & $28(6.3 \%)$ & $14(3.2 \%)$ & \multirow{3}{*}{0.083} \\
\hline & 7-9 hours & $271(85.5 \%)$ & $97(77.6 \%)$ & \\
\hline & More than 9 hours & $18(5.7 \%)$ & $14(11.2 \%)$ & \\
\hline
\end{tabular}

Table 3: Genderwise correlation (Pearson) of age and BMI with sleep duration

\begin{tabular}{|l|c|c|c|c|}
\hline \multirow{2}{*}{ Characteristics } & \multicolumn{2}{|c|}{ Sleep duration in males } & \multicolumn{2}{c|}{ Sleep duration in females } \\
\cline { 2 - 5 } & Coefficient of correlation & P value & Coefficient of correlation & P value \\
\hline Mean age & 0.166 & 0.003 & 0.018 & 0.846 \\
\hline BMI & 0.036 & 0.558 & 0.004 & 0.964 \\
\hline
\end{tabular}

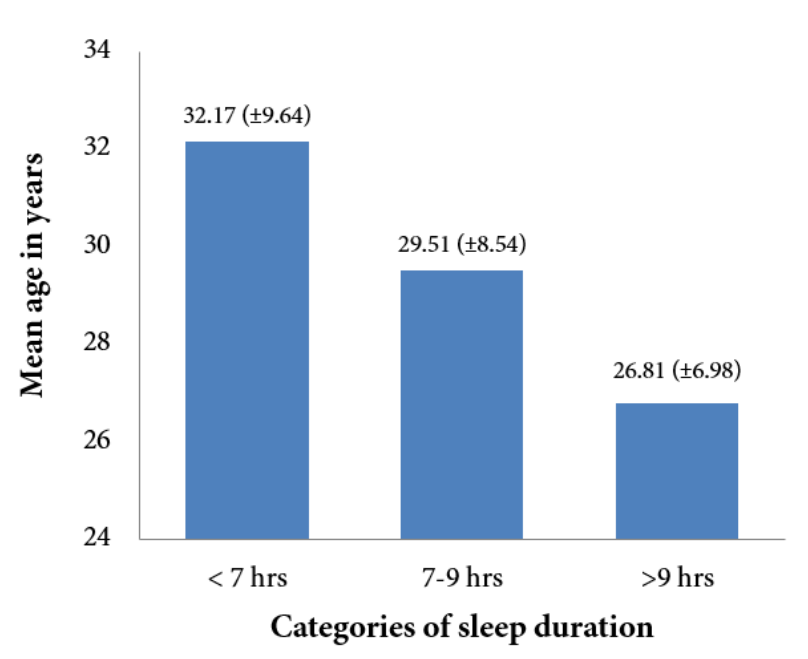

Figure 1: Comparison of average age of participants in different sleep categories participants in each sleep caterogy was comparable in males and females ( $\mathrm{p}=0.79$, ANOVA).

Genderwise correlation was explored for the duration of sleep with age and BMI (Table 3). It was noticed that in males, there was an inverse and significant correlation of sleep duration with age. In females, significant correlation between age and sleep duration was not observed. There was no significant correlation of BMI with sleep duration in either group.

\section{DISCUSSION}

Apparently healthy adult males and females of comparable age and body mass index constituted the study groups. It was found that women went to bed about 20 minutes earlier and woke up in the morning about half an hour earlier than men, 
which were both significant differences. However, the total duration of sleep was comparable (nearly eight hours). Our findings are in agreement with most of the other studies.

A consolidated sleep duration of 7-9 hours has been recommended for adults and young adults (18-64 years age).[11] The majority of participants of this study (83.36\%) had this duration of sleep. A decrease in sleep duration as the person gets older is also recognized.[1] Longer sleep hours in younger age group was also observed in this study (Figure 1). In a large scale study $(\mathrm{n}=2252)$, Park et al (2001) have reported late bedtime and longer sleep in younger people and earlier bedtime with increase in age.[12]

Differences between male and female in sleep time as well as sleep quality have been frequently observed, probably because of differences in social and domestic roles or customs in the society.[1,12] The gender difference in sleep time and quality is also associated with physiological and psychological differences.[10,13] This study demonstrated significant differences in time to bed and wake up time between males and females. Most studies have highlighted on the quality of sleep, such as in terms of sleep interruptions, nightmares, awakening time, and various sleep disorders. Identifying the nature of gender differences in sleep has potential to improve care of both men and women in relation to sleep disorders. Further, studies have also linked different characteristics of sleep to other disorders such as obesity, hypertension, pneumonia risk, and musculoskeletal problems.[3,4,6,14] Lately, television viewing and computer, mobile phone use have strongly impacted sleep habit of people, especially school children.[15,16] These associations and aspects of sleep were not explored in this study due to limited contact time with the participants.

Some studies have also reported the association of shorter sleep duration with increased weight gain. This has led to the suggestion that lack of sleep could be a risk factor for overweight and obesity. $[14,17]$ Inadequate sleep then could also be a risk to obesity-related cardiovascular and other disesases. In this study, significant correlation was not seen between the two variables, in either sex group. The higher age of the participants could have made this correlation inapparent. Most of the other studies were conducted in pediatric or adolescent population.

\section{CONCLUSION}

Most of the study participants have a sleep duration of 7-9 hours, which is considered adequate by most recommendations. Duration of sleep seems to decrease with increasing age; the relation is not so pronounced in females. Although male and female groups had equal durations of sleep hours, the time of day of their sleeping habits is significantly different. Females go to bed earlier and wake up earlier than males. Gender-wise comparison of sleep habit of Nepalese adults has not been reported. Further explorations on sleep quality, associations with television and mobile phones, occupational characteristics, and sleep disorders are recommended in future studies. The findings could be useful in managing sleep disorders and associated psychosocial issues in the Nepalese population.

\section{CONFLICT OF INTEREST}

None

\section{REFERENCES}

1. Waterhouse J, Fukuda Y, Morita T. Daily rhythms of the sleep-wake cycle. J Physiol Anthropol. 2012;31(1):5. Available from: http://www.jphysiolanthropol.com/ content $/ 31 / 1 / 5$

2. Barrett KE, Barman SM, Brooks HL, Yuan J, editors. Ganong's review of medical physiology. 26th ed. McGraw Hill Education; 2019.

3. Patel SR, Malhotra A, Gao X, Hu FB, Neuman MI, Fawzi WW. A prospective study of sleep duration and pneumonia risk in women. Sleep. 2012;35(1):97-101.

4. Gangwisch JE, Heymsfield SB, Boden-Albala B, Buijs RM, Kreier F, Pickering TG, et al. Short sleep duration as a risk factor for hypertension: Analyses of the first National Health and Nutrition Examination Survey. Hypertension. 2006;47(5):833-9.

5. Gottlieb DJ, Redline S, Nieto FJ, Baldwin CM, Newman $A B$, Resnick HE, et al. Association of usual sleep duration with hypertension: The Sleep Heart Health Study. Sleep. 2006;29(8):1009-14.

6. Gordon SJ, Grimmer KA, Trott P. Sleep position, age, gender, sleep quality and waking cervico-thoracic symptoms. Internet J Allied Heal Sci Pract. 2007;5(1):1-8. Available from: http://ijahsp.nova.edu

7. Ferrie JE, Shipley MJ, Akbaraly TN, Marmot MG, Kivimäki M, Singh-Manoux A. Change in sleep duration and cognitive function: Findings from the Whitehall II study. Sleep. 2011;34(5):565-73. 
8. Kryger M, Zee P. Sleep-Wake Cycle: Its Physiology and Impact on Health. Natl Sleep Found. 2006;1-19. Available from: http://www.ut.ngb.army.mil/19sf_fp/Documents/ Tough Topics/Sleep-Wake_Cycle.pdf

9. Blair ML. Sex-based differences in physiology: What should we teach in the medical curriculum? Am J Physiol - Adv Physiol Educ. 2007;31(1):23-5.

10. Burgard SA, Ailshire JA, Hughes NM. Gender and sleep duration among American adults. 2010.

11. How much sleep do you need?. Sleep Health Facts. Sleep Health Foundation; 2011. p. 1-6. Available from: https://www.sleephealthfoundation.org.au/pdfs/ HowMuchSleep-0716.pdf

12. Park YM, Matsumoto K, Shinkoda H, Nagashima H, Kang MJ, Seo YJ. Age and gender difference in habitual sleep wake rhythm. Psychiatry Clin Neurosci. 2001;55:201-2.

13. Mallampalli MP, Carter CL. Exploring sex and gender differences in sleep health: A society for women's health research report. J Women's Heal. 2014;23(7):553-62.

14. Chaput J, Després J, Bouchard C, Tremblay A. The association between sleep duration and weight gain in adults : a 6-year prospective study from the Quebec Family Study. Sleep. 2008;31(4):517-23.

15. Owens J, Maxim R, Mcguinn M, Nobile C, Msall M, Alario $A$, et al. Television-viewing habits and sleep disturbance in school children. Pediatrics. 1999;104(3):18. Available from: https://pediatrics.aappublications.org/ content/pediatrics/104/3/e27.full.pdf

16. White AG, Buboltz W, Igou F. Mobile phone use and sleep quality and length in college students. Int J Humanit Soc Sci. 2010;1(18):51-8.

17. Garaulet M, Ortega FB, Ruiz JR, Rey-López JP, Béghin $L$, Manios $Y$, et al. Short sleep duration is associated with increased obesity markers in European adolescents: Effect of physical activity and dietary habits. the HELENA study. Int J Obes. 2011;35(10):1308-17. 